\title{
What scientists should focus on — and fear — under Trump
}

Nine experts reflect on where researchers should direct their efforts during the next US administration.

11 November 2016

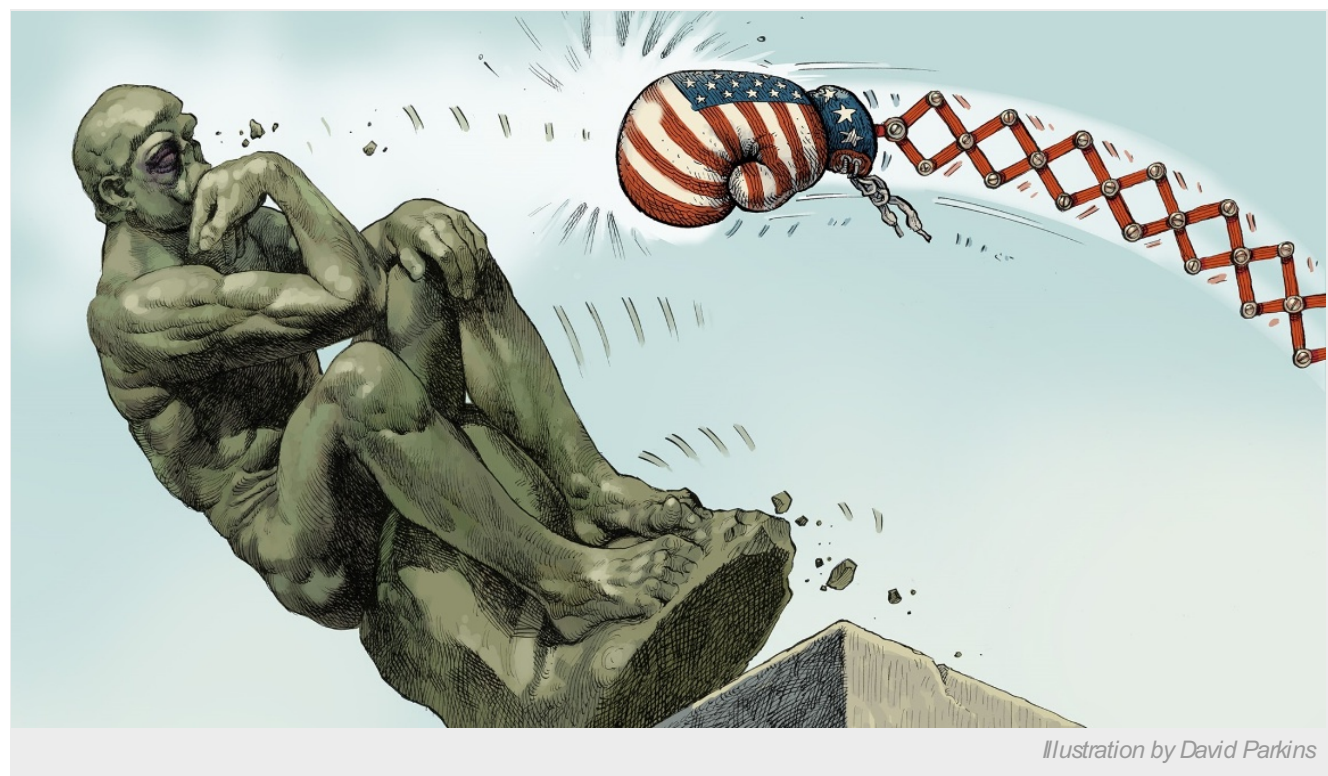

How should researchers prepare for the presidency of Donald Trump? Nature asked nine experts in science and the humanities to lay out their advice and concerns ahead of the next US administration.

Douglas Sipp: Beware of plans to lower drug standards

Daniel M. Kammen: Back clean energy to create jobs

Stuart Russell: Tiptoe through the nuclear minefield

Lars Brozus \& Oliver Geden: Study policymaking

John Krige: Preserve the post-war contract

Elena Cattaneo: Draw strength from past struggles

David Kaiser: Share the joy of science

Nathaniel Comfort: Reinstate Enlightenment values

Cassidy Sugimoto: Strengthen study of disparities and stay global

\section{Beware of plans to lower drug standards}

Douglas Sipp, Riken Center for Developmental Biology, Kobe, Japan

Supporters of the idea that drugs should be tested for efficacy before being sold are in for a long four years. In recent years, Republican majorities in the Senate and in the House of Representatives have backed several bills that would drastically reduce the authority of the US Food and Drug Administration (FDA), and its ability to require that new medical products are demonstrated to be safe and effective before they are marketed.

Most concerning is the Republican push for a federal 'right to try' law, which would indemnify companies and individual physicians that sell experimental drugs to dying patients after only preliminary safety testing.

Similar laws have been enacted in 32 states. But these have had little impact, being superseded by federal code. A federal right-to-try law would effectively make phase I clinical trials (which test safety) the threshold for marketing new products. This would have profound consequences - on how new drugs are brought to market, and for clinical-trial enrolment. The right-to-try movement is making overtures overseas too. In Canada, for example, all members of its parliament received a coordindated e-mail calling on them to endorse such a law.

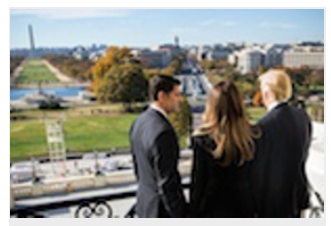

The ultimate experiment: How Trump will handle science 
been stalled in a Senate committee since this spring. Major scientific groups have issued statements opposing the act, including the International Society for Stem Cell Research, the International Society for Cellular Therapy, and the Alliance for Regenerative Medicine. The bill's prospects had seemed grim. Substantive amendments in recent months had, for instance, removed an alarming call for Congress to prohibit the FDA from requiring phase III clinical trials, typically the final hurdle for therapies to be approved for market for most investigational cell therapy products. Now, under a Republican-dominated government, its dim chances seem to have brightened.

Other attempts at deregulation may also take advantage of the new, effectively one-party government. These include proposals to lower evidence standards for drug approval across the board, and to undermine FDA authority over the promotion of 'off-label' uses of approved drugs.

\section{Back clean energy to create jobs}

Daniel M. Kammen, Director of Renewable and Appropriate Energy Laboratory (RAEL), University of California, Berkeley

If Trump's business bona fides are all he claims, he should see that the smart money is on clean energy. Clean-energy projects generate more jobs than do the coal and natural-gas sectors. With solar and wind projects creating energy prices between 2.5 and $4 \phi$ per kilowatt-hour, the economic case is compelling — as is the argument for these technologies being the fastest way to provide energy access to the global poor, boosting their economic opportunities and capacity.

The economic benefits of clean energy are even more profound if combined with domestic manufacturing of electric vehicles, which bring new research growth to the high-tech sector. Renewable-energy options, in some cases supported by natural gas, are a faster route out of energy and economic poverty than are coalenergy projects.

And the global energy markets are embracing the clean-energy transition. Jordan, Kenya, Morocco, Nicaragua and many other nations are merging the business and environmental case to push for and beyond the goals of the Paris climate agreement, which became legally binding last week and from which

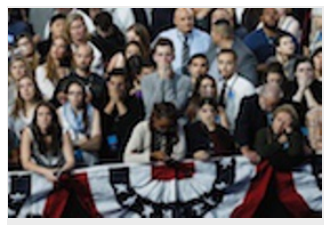

How scientists reacted to the US election results Trump has pledged to withdraw the United States. These countries are building gigawatt-scale clean-energy plants, and ramping up their innovation and industrial sectors at the same time.

As shown by the activity at COP22, the United Nations climate summit currently happening in Marrakesh, Morocco, the world will be pursuing clean-energy and climate-friendly goals with or without the United States. It would be folly not to want to lead and profit from this transition.

\section{Tiptoe through the nuclear minefield}

Stuart Russell, Director of the Center for Intelligent Systems, University of California, Berkeley

I have two concerns about defence policy. First, I'm not optimistic that the White House will understand the negative humanitarian and strategic consequences posed by lethal autonomous weapons systems. The Obama administration took the views of the scientific community seriously in formulating foreign and military policy.

Secondly, I fear for the Comprehensive Nuclear-Test-Ban Treaty, one of the pillars of global nuclear nonproliferation policy. Trump has disparaged the Iran nuclear agreement to limit that country's nuclear programme; the deal is widely supported by arms-control experts. He has said that he has no objection to allowing several countries in Asia and the Middle East to have nuclear weapons. He has announced his intention to retaliate with nuclear weapons against a terrorist attack by ISIS (where, exactly, would he detonate them?).

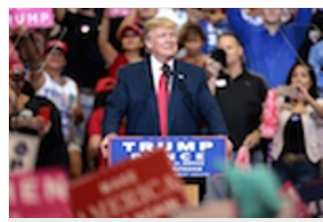

Science under President Trump

The world has been tiptoeing through a nuclear minefield for seven decades and perhaps the exit was in sight. With Trump, we could plunge back into the minefield, running blindfold and flailing our arms.

\section{Study policymaking}

Lars Brozus \& Oliver Geden, German Institute for International and Security Affairs, Berlin 
how relevant are policymakers for policymaking? The question is not as frivolous as it sounds.

For decades, social scientists have come up with different claims about who and what influences political decisions and governmental action. Two broad camps have emerged: one, mostly led by historians, stipulates that it is 'big men' (historically) that make 'big policy'. The other camp, mostly peopled by political scientists, explains policies as the product of opportunities, interests and timing. The hostile takeover of Washington's bureaucracy by a deeply divided Republican party will shed more light on these questions.

\section{Preserve the post-war contract}

John Krige, Professor in the School of History and Sociology, Georgia Institute of Technology, Atlanta

I fear that the humanities will be targeted as being economically irrelevant. I fear that social-science research that is deemed too critical of government policy or of social trends (police or gun violence, or toxic poverty, for example) will suffer as being driven by 'liberal bias'. The commercialization of universities, already under way, will accelerate. The right to carry guns on campus, and into classrooms, is likely to be aggressively asserted.

As funding decreases, US public universities will increasingly view foreign students as a commodity who can be charged full out-of-state tuition. Applicants from abroad will balance the benefits of being trained at cutting-edge research universities against a rising tide of xenophobia, tightened restrictions on knowledge circulation with non-US citizens, and increased costs.

International scientific and technological exchange, especially with China, is threatened, and will be caught in the backlash of the trade wars envisioned by Trump during his campaign. Major international agreements on climate change and on controlling the spread of nuclear weapons could be shredded. Trump's victory, along

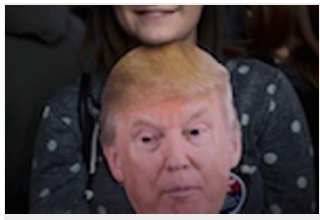

The scientists who support Donald Trump with the Republican-controlled Congress, accelerates the end of the post-war contract between science, technology, higher education and the state.

\section{Draw strength from past struggles}

Elena Cattaneo, Director of the Centre for Stem Cell Research, University of Milan, Italy

The US scientific community has shown that its commitment to reasoned argument can prevail in the most difficult circumstances.

When George W. Bush banned public funding for embryonic stem-cell research in 2001, researchers mobilized in a landmark campaign. They tapped every resource, from private foundations and associations to the public. That focus on strong, pragmatic debate saw the prohibition reversed in 2009. Yet all the while, the nation's scientists have delivered remarkably solid results that we all have been using to further our own research.

My high regard for US scientists gives me hope that their bold, empirical thinking can provide the 'antibodies' to contain and temper any risk to the noble and democratic traditions of a United States that still has so much to offer the world.

\section{Share the joy of science}

David Kaiser, Professor of the History of Science, and of Physics, Massachusetts Institute of Technology, Cambridge

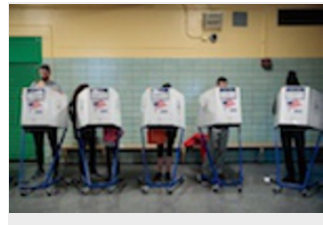

Pollsters struggle to explain failures of US presidential forecasts

The biggest immediate challenge for science and scientists will likely be further pressure to cut federal funding for research. This is likely to exacerbate the current trend of funding short-term projects that might promise short-term pay-off, combined with greater uncertainty from one grant-cycle to the next. These trends have made it difficult to do any sort of responsible planning for medium-term — let alone long-term — projects.

Think of LIGO. The research collaboration's successful detection of gravitational waves last year was the culmination of decades of sustained support from the US federal government, through the National Science Foundation. Project leaders could plan responsibly for next steps and recruit young scientists and technicians to the project with some confidence about continued ability to support their roles. It is difficult to imagine big, complicated projects that require even a fraction of the time that LIGO needed receiving reliable support today, and that was true even before the election. 
Scientists and scholars must continue to articulate the value of supporting research. Some of that value has an from technology transfer - in the form of commercialized products or health-related advances. But there is also a real need to raise awareness about the less-tangible, long-term benefits that are less evident to taxpayers and politicians.

I am heartened by the incredible interest that the LIGO discovery generated throughout the world. Many people remain fascinated by big-picture, imaginative research - even that which does not lead quickly to better gadgets or drugs. Similar excitement greeted the Higgs-boson discovery in 2012. More than ever, we must make the case that abstract, long-term projects deserve taxpayer support.

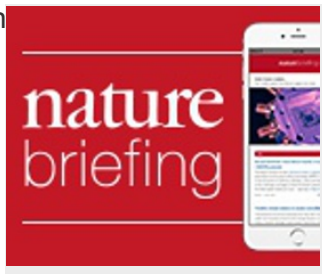

The best science news from across the web, direct to your inbox - free!

\section{Reinstate Enlightenment values}

Nathaniel Comfort, Professor, Department of the History of Medicine, Johns Hopkins University, Baltimore, Maryland

Trump's success is the crescendo of a long devaluation of the Enlightenment idea that facts are the rightful basis of action. Reason itself is under fire. This mistrust of expertise is a serious threat to the sciences and the humanities.

Science is in the business of making knowledge. History is founded on the principle that informed reflection is superior to ignorance. Devaluing evidence and manufacturing doubt can be a powerful strategy — as climate-change deniers and the tobacco industry have shown. Their push for short-term gain threatens our health and environment.

The history of science, broadly construed, must shoulder some of the blame. Perhaps the central insight of my field in the past 40 years is that facts are socially constructed. Truth has a social history. But even the most extreme social constructionists still value expertise; they are not the ones trying to destroy the fabric of reality. This subtlety has been lost on the wider public, and to some extent on scientists. The rift between the arts and sciences — the pillars of the university — now threatens all who value reason.

The sciences and humanities must join forces and push back. We must reinstate Enlightenment values — modulated now by an appreciation of their social nature - in politics and culture. Together we can restore trust in expertise, by re-enrolling non-experts in our projects. Make the public once again feel invested in knowledge. Speak truth to power.

\section{Strengthen study of disparities and stay global}

Cassidy Sugimoto, School of Informatics and Computing, Indiana University Bloomington

My research examines who gets to make knowledge, share knowledge, and be given credit for that knowledge. I explore how gender and other biases frame credibility and authority. I study how social disparities are reproduced and legitimized in the academic sphere: how do disparities suppress the voice and labour of some, while disproportionately magnifying others?

This election cycle reconfirmed the realities of these disparities, with immediate repercussions for science. The devaluing discourse of the campaign endangers the strides we have made towards equality in the scientific workforce. The platform of isolationism threatens the ability of the United States to fully engage in the global knowledge economy.

The strength of the scientific workforce in the United States depends on the ability to recruit and retain a diverse and global scientific workforce. US Nobel prizes and other great discoveries are largely attributed to scholars both born and educated in other countries. High impact work — and the knowledge economy — require international mobility and collaboration. If US policies and rhetoric inhibit our ability to work at the global level, the strength of the United States, both scientifically and economically, will decline.

As educators and scholars, we must use the election to teach our students about critical thinking and civil discourse. We must continue to demonstrate to all students — regardless of race, gender, sexuality, ability or religion — that they are valuable and can contribute to knowledge and society. We must strengthen our bonds with scholars from across the world. We must demand that the government continue to invest in public education — the cornerstone of a functioning democracy.

Finally, we must continue to conduct research that helps us to understand the forces that perpetuate disparities and the ways in which we can, individually and collectively, ensure that all people can contribute to and have access to knowledge. 